\title{
Regio- and Stereoselectivity in the Paternò-Büchi Reaction on Furan Derivatives
}

\author{
Maurizio D’Auria, Lucia Emanuele, and Rocco Racioppi \\ Dipartimento di Chimica, Università della Basilicata, Via N. Sauro 85, 85100 Potenza, Italy
}

Received 16 March 2006; Revised 30 March 2006; Accepted 30 March 2006

\begin{abstract}
The photochemical coupling reaction between 2,3-dihydrofuran and benzaldehyde was studied by using DFT/B3LYP/6 - 31G + $(d, p)$ method. The regiocontrol of the attack of the benzaldehyde on the double bond is related to the different stabilities of the biradical intermediates. The endo stereoselectivity of the reaction depends on the superposition between HSOMO and LSOMO in the biradical intermediate. In the photochemical reaction between furan and benzaldehyde also the regiocontrol depends on the relative stability of the possible biradical intermediates. The exo stereoselectivity of the coupling reaction depends on the superposition between the HSOMO and LSOMO of the biradical intermediate. The reaction of chiral phenylglyoxylates with furan gave the corresponding adducts with de $=15-95 \%$. The stereocontrol can be explained considering the energy gap between the biradical intermediates in the coupling reaction. When the reaction was performed in the presence of zeolite, the diastereoisomeric excess increased. The reaction of benzoin and 2-phenylpropiophenone with furan gave the cycloadduct with high diastereocontrol. All the products were obtained with de $>98 \%$. The Paterrnò-Büchi reaction between 2-furylmethanols with aromatic carbonyl compounds also showed high regio- and stereocontrol. On the contrary, when 5-methyl derivatives were used, a lack of regiocontrol was observed. Furthermore, with aliphatic carbonyl compounds, no diastereoselectivity was observed. These results were explained assuming the attack of the excited carbonyl compound on the same side as the hydroxyl group, through the formation of a hydrogen bond or of a complex. This type of attack gave the biradical intermediate in preferential conformations. The relative energies of these conformers account for the observed diastereoselectivity.
\end{abstract}

Copyright (c) 2006 Maurizio D’Auria et al. This is an open access article distributed under the Creative Commons Attribution License, which permits unrestricted use, distribution, and reproduction in any medium, provided the original work is properly cited.

\section{INTRODUCTION}

$[2+2]$-cycloadditions are one of the most important reactions in organic photochemistry. Several applications in organic synthesis have been described [1]. The Paternò-Büchi reaction is a $[2+2]$-cycloaddition reaction between a carbonyl compound and an alkene (Scheme 1(a)). The regiochemistry of this reaction appeared to be a difficult problem to solve from the first. Paternò performed a reaction between 2-methyl-2-butene and benzaldehyde, and he could not assign the exact structure of the product. He was not able to distinguish between $\mathbf{1}$ and $\mathbf{2}$ (Scheme 1(b)) [2]. Büchi solved the problem showing that $\mathbf{1}$ was the actual product [3]. Furthermore, in this reaction the stereocontrol was not examined, but several stereoisomers could be obtained.

Regio- and stereocontrol of the Paternò-Büchi reaction was not always understood. For several years the comprehension level of these two factors resembled the description of some problems connected with the evolution of photo- chemistry made by Ciamician in 1912: "in ordinary organic chemistry the reactions often take place in some definite way; but the photochemical reactions often furnish surprises and proceed along quite different lines" [4].

The Paternò-Büchi reaction is a photocycloaddition of an $n, \pi^{*}$ carbonyl compound in either its $S_{1}$ or the $T_{1}$ state to an alkene in its ground state. In a theoretical study the authors showed that there are two conical intersection points located near the $\mathrm{C}-\mathrm{C}$ and $\mathrm{C}-\mathrm{O}$ bonded biradical regions of the ground state [5]. Furthermore, for $\mathrm{C}-\mathrm{O}$ attack, the triplet surface must cross the singlet to reach a diradicaloid minimum.

For $\mathrm{C}-\mathrm{C}$ attack, the triplet state biradical minimum is located at the same geometry as the conical intersection between the two singlet states, and the efficiency of the intersystem crossing will be determined by the nature of the spinorbit coupling. Thus, for the triplet, the reaction path can be predicted by the most stable biradical rule [5]. The biradical intermediate in the reaction between benzophenone 


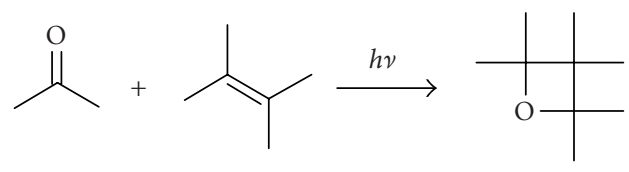

(a)

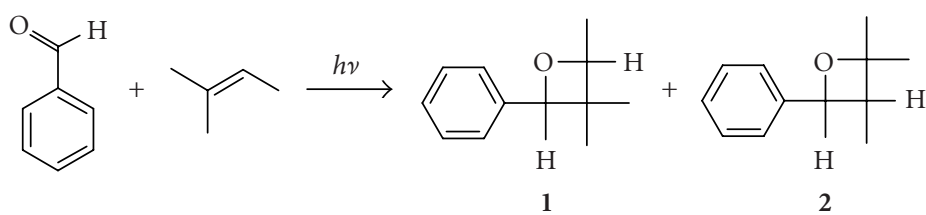

(b)

Scheme 1

and electron-rich alkenes has been determined by using laser flash photolysis $[6,7]$. A conformational analysis of the biradicals has been published [8].

Furan derivatives can give the Paternò-Büchi reaction reacting with carbonyl compounds. This reaction has been used extensively in the synthesis of natural products $[9,10]$.

In order to explain both regio- and stereocontrol of the Paternò-Büchi reaction on furan derivatives, we used the pattern represented in the Scheme 2 on the basis of the work of Scharf [11]. We assumed that the formation of the possible biradicals is reversible. The consequence of this hypothesis is, in agreement with the theoretical study, that the formation of the more stable intermediate is preferred, while all the other isomers undergo retrocleavage. The following ring closure is an irreversible step, determined by spin-orbit coupling [12-14], that usually allowed the formation of the more stable compound [15].

Obviously, in the presence of achiral precursors, $k_{1}=k_{2}$ as well as $k_{3}=k_{4}$. In the presence of chiral reagents or in a chiral environment, we can observe $k_{1} \neq k_{2}$ and $k_{3} \neq k_{4}$.

\section{THE PATERNÒ-BÜCHI REACTION ON FURAN DERIVATIVES}

\subsection{2,3-dihydrofurans}

The irradiation of 2,3-dihydrofuran (3) with benzophenone gave the head-to-tail adduct 4 [16]. The same behaviour was observed irradiating 2,3-dihydrofuran with aliphatic aldehydes or ketones. By using acetone the adducts were obtained in a $200: 1$ isomeric ratio [17].

When benzaldehyde was used as carbonyl compound, the adducts were obtained as a $>98: 2$ regioisomeric mixture. The major isomer is $88: 12$ endo/exo mixture (Scheme 3). The reaction showed a good regio- and stereoselectivity [1820]. Benzaldehyde reacts in its triplet state. A triplet biradical is formed as an intermediate.

We examined the regiochemistry of the reaction, and we tested the possibility that the regiochemical behaviour of the reaction is determined by the formation of the more stable biradical intermediate. We performed DFT/B3LYP calcula- tions using $6-31 G+(d, p)$ basis set on Gaussian 03. We examined the structures $\mathbf{M}$ and $\mathbf{N}$ (Figure 1).

The biradical $\mathbf{N}$ is more stable than $\mathbf{M}$ by $1.49 \mathrm{kcal} \mathrm{mol}^{-1}$. This result is in agreement with the experimental result. On the basis of this result the stability of the biradical intermediates can account for the regiochemical behaviour of the reaction.

We can see also why the endo isomer is favoured in the reaction. In Figure 2 we have depicted the HSOMO and the LSOMO of the biradical N. The HSOMO is mainly localized on the aromatic ring and it is extended on the benzylic radical site. The LSOMO is mainly localized on the dihydrofuran ring. The coupling between the radical carbons in these two orbitals is possible (the atomic orbitals involved can superimpose themselves) only if the endo isomer is formed (Figure 3).

\subsection{Furans}

\subsubsection{Photoaddition of benzaldehyde and benzophenone}

Schenck reported that the irradiation of benzophenone in furan gave the head-to-head adduct in 94\% yield $[21,22]$. The analogous photoadduct 6 of benzaldehyde to furan (5) [23] has the 6-exo configuration as confirmed by NOE analysis (Scheme 4) [24, 25].

We also examined for this case the regioisomeric biradical intermediates $\mathbf{O}$ and $\mathbf{P}$ resulting from the head-to-head and the head-to-tail addition, respectively (Figure 4).

The biradical $\mathbf{O}$ is more stable than $\mathbf{P}$ by $16.5 \mathrm{kcal} \mathrm{mol}^{-1}$. The biradical $\mathbf{O}$ exists as two conformers and we considered only that conformer able to give the ring closure. The HSOMO and LSOMO of the biradical $\mathbf{O}$ are reported in Figure 5.

Also in this case the HSOMO is mainly localized on the benzaldehyde fragment of the biradical while the LSOMO is mainly localized on the furanoid part of the molecule. The coupling between the radical carbons in these two orbitals, considering that the atomic orbitals involved can superimpose themselves, can give only the exo isomer, in agreement with the experimental results (Figure 6). 


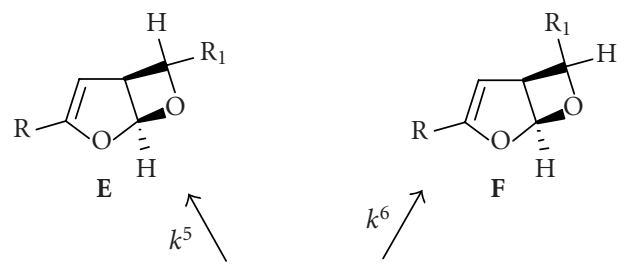<smiles>[R]C1O[C@]2([R])OC=C[C@@H]12</smiles>

$k^{9} \uparrow$<smiles>[R1]C([R])O[C@]1([R])CC=CO1</smiles>

D<smiles>[R]C1O[C@]2([R])OC=C[C@H]12</smiles>

L<smiles>[R1]CO[C@@H]1CC=C([R])O1</smiles>

A

$k^{1} \uparrow \mid k_{-1}^{1}$<smiles>[R]C1O[C@]2([R])OC=C[C@@H]12</smiles>

$k^{9} \uparrow$<smiles>[AlH]</smiles><smiles>[R]c1ccco1</smiles><smiles>CC=CCCCCCCCCC</smiles><smiles>[Y1]1=CC=[V]C1</smiles><smiles>[R1]CO[C@@H]1CC=C([R])[C@H]1[B]</smiles>

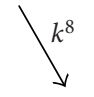<smiles>[R1]C([CH])O[C@]1([R])CC=CO1</smiles>

C<smiles>CC[Te]</smiles><smiles>[R]C1O[C@]2([R])OC=C[C@@H]12</smiles><smiles>[R]C1=C[C@@H]2O[C@@H]([R1])[C@H]2C1</smiles><smiles>[R]C1=C[C@@H]2CO[C@H]([R1])[C@@H]2O1</smiles>

$\mathrm{H}$

Scheme 2<smiles>C1=COCC1</smiles>

$+\mathrm{PhCHO}$<smiles>CCO</smiles><smiles>c1ccc(C2OC3CCOC32)cc1</smiles>

4

Scheme 3

\subsubsection{Photoaddition of chiral carboynl compounds to furans}

We studied the photocycloaddition of three enantiopure phenylglyoxylates, namely, compound 7, obtained from $(S)$ 1-methyl-1-propanol, compound 8, obtained from $(S)$-2methyl-1-butanol, and compound 9, obtained from (-)-8phenylmenthol (Figure 7) [26].

All the reactions gave in good yields the corresponding oxetanes. Considering the stereocontrol of the reaction, while the reaction with 8-phenylmenthol glyoxylate gave a high di-

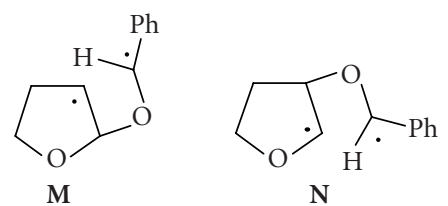

FIGURE 1: Possible biradical intermediates in the reaction of 2,3dihydrofuran with benzaldehyde.

astereoisomeric excess, the reaction with the glyoxylate ester 7 gave only 15\% de and the reaction with the glyoxylate ester 8 resulted in no diastereoselectivity (Figure 7).

The best results in order to justify the observed stereoselectivity can be obtained considering the energy of the triplet biradical intermediates in the reaction of 7-9 with furan (Figure 8).

Calculations on these biradical intermediates showed that $\mathbf{Q a}$ (the precursor of 10) was more stable than $\mathbf{Q b}$ by 


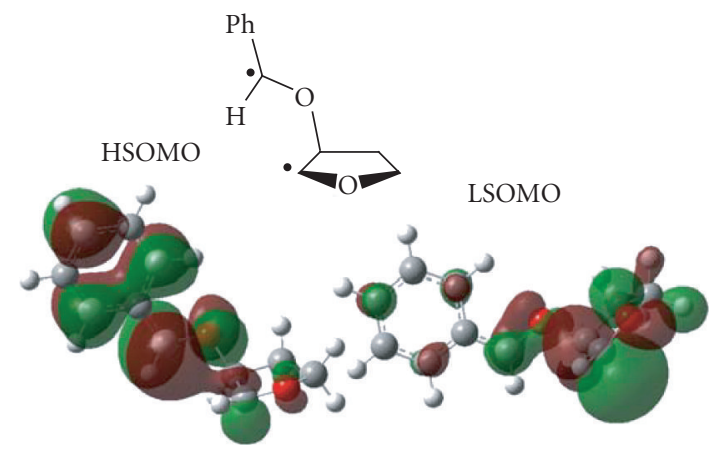

FIGURE 2: HSOMO and LSOMO of the biradical intermediate N.

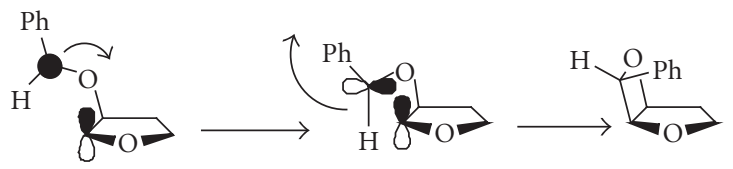

FIGURE 3: Ring-closure reaction in the formation of the endo isomer of the adduct between 2,3-dihydrofuran and benzaldehyde.<smiles>c1ccoc1</smiles><smiles></smiles>

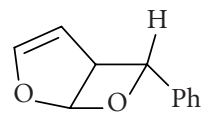

6
SCHEMe 4

$0.73 \mathrm{kcal} \mathrm{mol}^{-1}$. Furthermore, $\mathbf{R a}$ and $\mathbf{R} \mathbf{b}$ differed by only $0.02 \mathrm{kcal} \mathrm{mol}^{-1}$, in agreement with the observed lack of stereoselectivity of the reaction. Finally, the biradical intermediate $\mathrm{Sa}$ showed to be more stable than $\mathrm{Sb}$ by $21.9 \mathrm{kcal} \mathrm{mol}^{-1}$ : also this result is in agreement with the observed high diastereoisomeric excess.

In conclusion, the stereocontrol of the Paternò-Büchi reaction between 7-9 and furan can be explained considering the relative stability of the possible biradical intermediates.

To improve diastereoselectivity, we tried to carry out a reaction in an organized medium (zeolite). Selective absorption on the surface of the solid $(\mathrm{NaY})$ could improve diastereoselectivity. We obtained the adducts 10-12. It is noteworthy that this type of procedure allowed us to improve diastereoselectivity: while, in the reaction in solution, 10 was obtained with de $=15 \%$, the reaction in an organized medium gave de $=37 \%$. While 11 was obtained as a mixture of diastereoisomers, the use of the zeolite allowed to reach $18 \%$ diastereoisomeric excess. Also in the case of 12, obtained in solution with de $=95 \%$, the use of the zeolite increases the diastereoisomeric excess reaching the value of 98\%.

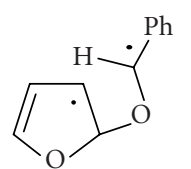

O

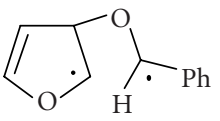

$\mathbf{P}$
FIgure 4: Possible biradical intermediates in the reaction of furan with benzaldehyde.

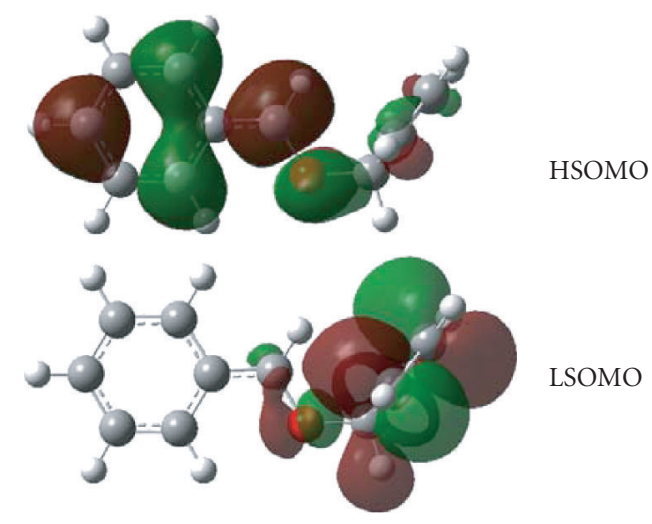

Figure 5: HSOMO and LSOMO of biradical intermediate $\mathbf{O}$.

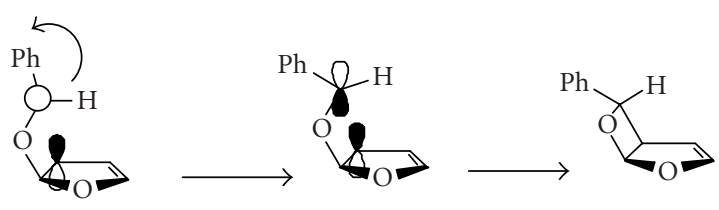

FIGURE 6: Ring-closure reaction in the formation of the exo isomer of the adduct between furan and benzaldehyde.

If the chiral center is near the reaction site, the diastereoselectivity increases. Benzoin (13) reacted with furan to give the corresponding adduct 14 in acceptable yield (56\%) and de $>98 \%$ (Figure 9) [27].

Also in this case we calculated the energy of the intermediates $\mathrm{Ta}$ and $\mathrm{Tb}$ for the reaction of benzoin with furan. The structures are depicted in Figure 10. The biradical Ta was more stable than $\mathbf{T b}$ for $3.66 \mathrm{kcal} \mathrm{mol}^{-1}$, in agreement with the observed stereoselectivity.

When chiral ketones were used as substrates we obtained products deriving from the Norrish Type II raction. In order to avoid Norrish Type II reaction we used a substrate without $\gamma$-hydrogen. We used the phenyl derivative 16 (Figure 11). In this case we observed the formation of the corresponding adduct [28].

The NMR data for the compound $\mathbf{1 6}$ are in agreement for an exo position for the phenyl group at $\mathrm{C}-6$. Chiral HPLC (Chiralcel OJ, $\lambda=235 \mathrm{~nm}, 99: 1 n$-hexane/isopropanol) showed a de $>98 \%$.

We calculated the total energy of the possible intermediates in the reaction of $\mathbf{1 5}$ with furan. The structures of these compounds (Ua, 1Ub) are showed in Figure 12. 
<smiles>CC[C@H](C)OC(=O)[C@@]1(c2ccccc2)O[C@@H]2OC=C[C@H]21</smiles><smiles>CC[C@H](C)COC(=O)[C@@]1(c2ccccc2)O[C@@H]2OC=C[C@H]21</smiles>

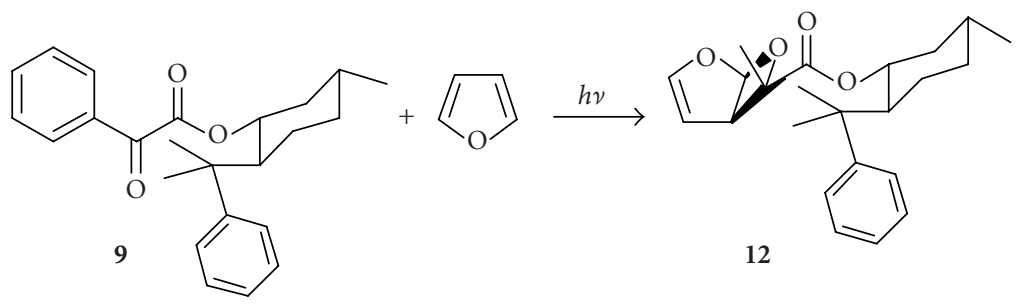

Figure 7: The reaction of chiral phenylglyoxylates with furan.

The $R, S$ conformer $\mathbf{U b}$ is more stable than the $S, S$ one by $1.1 \mathrm{kcal} \mathrm{mol}^{-1}$ and this difference can account for the observed diastereoselectivity.

Furthermore, the analysis of the HSOMO and LSOMO in this biradical intermediate (Figure 13) shows that the coupling can occur to give the product with the phenyl group in the exo configuration.

\subsubsection{Photoaddition of carbonyl compounds to chiral furans}

The diastereoselectivity of the Paternò-Büchi reaction can be determined in the presence of some substituents, that is, the presence of chiral substituents on the alkene. Adam showed that allylic alcohols 17 reacted with benzophenone to give the corresponding adducts 18 and 19 with high region- and diastereoselectivity (Scheme 5) [29-32].

The diastereoselectivity dropped drastically in the presence of the protic solvent methanol and totally disappeared for the corresponding silyl ethers. These data are in agreement with the presence of a hydroxyl directing effect in the Paternò-Büchi reaction. The threo isomer can be favoured through the formation of a hydrogen bond between triplet excited benzophenone and the substrate in the exciplex, while the formation of the erythro stereoisomer would be less favoured due to allylic strain (Scheme 6).

The formation of a hydrogen bond directing the PaternòBüchi reaction has been considered by other researchers.<smiles>CC[C@H](C)OC(=O)C(OC1CC=CO1)c1ccccc1</smiles><smiles>CC[C@H](C)COC(=O)C(OC1CC=CO1)c1ccccc1</smiles>

Ra<smiles></smiles>

Sa<smiles>CC[C@H](C)COC(=O)[C@H](OC1C=COC1)c1ccccc1</smiles>

Rb<smiles>CC1CCC2OC(=O)[C@H](c3ccccc3)OC(c3ccccc3)(c3ccco3)C2C1</smiles>

Sb
FIGURE 8: Radical intermediates in the reaction of 7-9 with furan. 


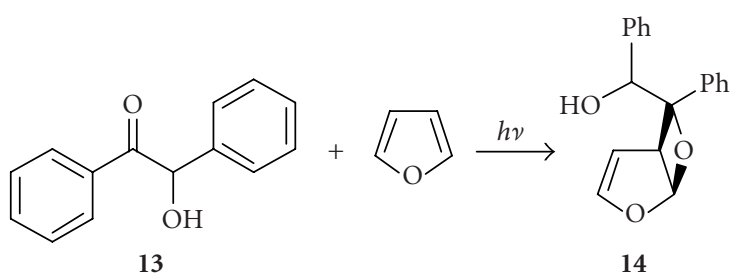

Figure 9: Photochemical reaction between benzoin and furan.

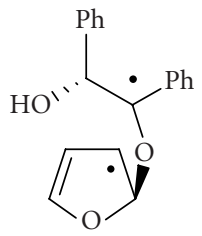

Ta

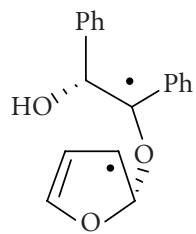

$\mathrm{Tb}$
FIGURE 10: Biradical intermediates in the reaction of benzoin with furan.

Diastereoselective cycloaddition has been obtained using chiral enamide $[33,34]$, or in the reaction of allylic alcohols with naphthalene rings [35]. When unsymmetrical carbonyl partners such as acetophenone or benzaldehyde were used, high diastereoselectivity was observed to give the corresponding cis isomer. The regioselectivity was high with acetophenone but lower with benzaldehyde [30].

Cis diastereoselectivity can be explained by using the Griesbeck rule on the possible triplet biradicals formed in the reaction. Steric interactions are minimized when the biradical assumes the optimal conformation and this conformation accounts for the formation of the observed stereoisomer [32].

When chiral allylic alcohols were used as substrates in the reaction, cis diastereoisomers were formed. Also in this case, a pronounced threo diastereoselectivity was observed, in agreement with a less pronounced hydroxyl directing effect when acetophenone and benzaldehyde were used $[30,32]$. A chiral allyl ether gave the corresponding adduct with high diastereoselectivity [36].

The reaction of allylic alcohols with carbonyl compounds was tested also on a particular type of allylic alcohol such as 2-furylmethanol derivatives. While the reaction of 2furylmethanol with benzophenone showed low regioselectivity, the presence of larger substituents on the carbon bearing the alcoholic function allows a high regioselectivity (Scheme 7) [37]. Furthermore, when 2-furylethanol (20) was used as substrate, a $1: 1$ mixture of stereoisomers was obtained, while, when 1-(2-furyl)-benzylic alcohol (21) was the substrate, only one diastereoisomer was obtained. The high diastereoselectivity observed was confirmed using optically active 21 .

The regioselectivity of the reaction was explained on the basis of the relative stability of the biradical intermediates. A theoretical study (DFT) showed that the biradical obtained on the most hindered side of the molecule was more stable than the other [38]. The nature of the intermediate was in agreement with the observed $\rho$ value in a Hammett free energy correlation.

When 5-methyl-2-furyl derivatives were used as substrates, a different regioselectivity was observed. Compound 22 gave a $1: 1$ mixture of regioisomers 25 and $\mathbf{2 6}$, when irradiated in the presence of benzophenone, and a single regioisomer $\mathbf{2 7}$ in the presence of benzaldehyde on the side bearing the methyl group (Scheme 7) [38]. In agreement with the results obtained with 2 -furyl derivatives, the products deriving from the attack on the side bearing the alcoholic function were obtained as a single diastereoisomer, while those deriving from the attack on the side bearing the methyl group were obtained as a mixture of diastereoisomers. Then, the hydroxyl group near the reaction center is needed to have diastereoselectivity.

The reaction of 2-furylmethanol derivatives with aliphatic aldehydes and ketones gave the corresponding adducts with high regioselectivity but no diastereoselectivity (Scheme 7) [39].

The observed diastereoselectivity in the reaction with aromatic carbonyl compounds clearly shows that it increases in relation to the nature of the substituents on the carbon bearing the alcoholic function as described by Adam. However, while Adam considers the allylic strain with a methyl group as the driving force for the diastereoselectivity [2931 ], in this case, the methyl group is not present. Therefore, the allylic strain cannot be used to explain diastereoselectivity.

In order to have more data to explain the observed stereoselectivity we studied the photochemical behaviour or tertiary 2-furylcarbinols [40]. The photochemical reaction of 1methyl-1-phenyl-1-(2-furyl)methanol 28 with benzaldehyde gave a mixture of two regioisomeric products 29 and $\mathbf{3 0}$.

The regioisomer on the most hindered side of the molecule was obtained in low yield but it showed a complete diastereoisomeric control. On the contrary the main product was a mixture of four diastereoisomeric products (Scheme 8 ). The reaction of the same compound $\mathbf{2 8}$ with benzophenone gave only the product deriving from the attack on the most hindered double bond of molecule 31 . This compound was obtained with $48 \%$ diastereoisomeric excess.

The reaction of 1-methyl-1-t-butyl-1-(2-furyl)methanol (32) with benzaldehyde and benzophenone showed complete regioselectivity. In all the experiments only the products deriving from the attack of the carbonyl compound on the most hindered double bond of the substrate were observed (Scheme 9).

The regiocontrol was explained, as described above, considering the relative stability of the biradical intermediates. In this case, in the reaction of the 1-methyl-1-phenyl-1(2-furyl)methanol with benzaldehyde the biradical obtained from attack on the less hindered double bond of the substrate was more stable than the other one by $18.03 \mathrm{~kJ} \mathrm{~mol}^{-1}$.

On the basis of these results we can attempt an explanation of the stereocontrol. 1-Methyl-1-phenyl-1-(2-furyl)methanol may exist in three conformations (Figure 14). All 


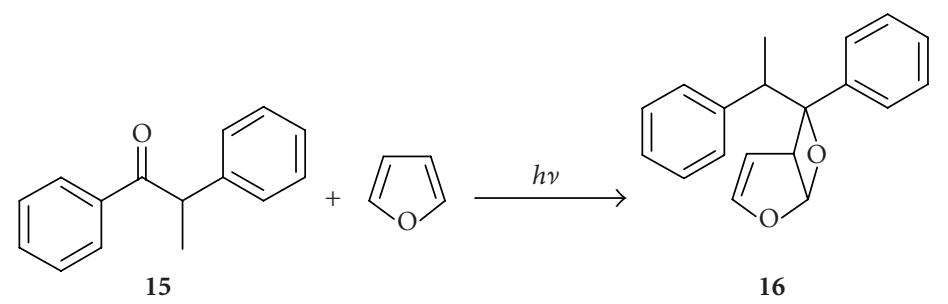

FIGURE 11: The photoaddition of rac 2-phenylpropiophenone to furan.

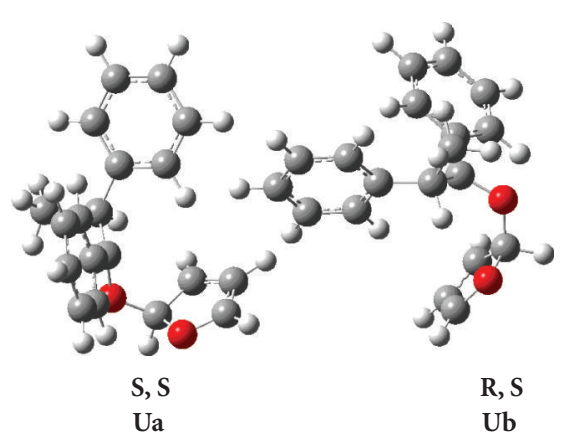

FIGURE 12: Biradical intermediates in the reaction between 15 and furan.

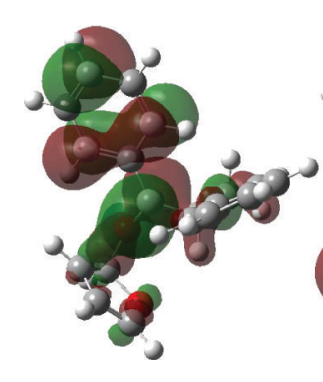

HSOMO

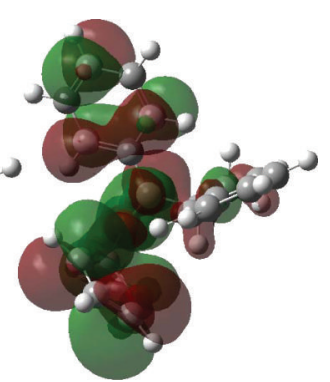

LSOMO
FIGURE 13: HSOMO and LSOMO of the biradical intermediate involved in the reaction between $\mathbf{1 5}$ and furan.

three conformers were in the range of $1.97 \mathrm{~kJ} \mathrm{~mol}^{-1}$ and they did not show a preference.

To solve the problem we tested the following hypothesis: the directing effect exerted by the hydroxyl group is either due to the formation of a hydrogen bond between the hydroxyl group and the oxygen of the excited carbonyl compound, or it is due to the formation of a complex. This type of interaction could favour the formation of a preferential conformation in the biradical intermediate where the hydroxyl group and the oxygen of the carbonyl compound are near. These conformations could have different energies for different diastereoisomeric biradicals, giving an explanation of the observed behaviour. The above hypothesis requires that the

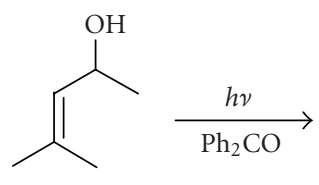

17

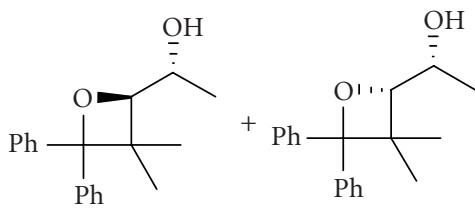

18

90

SCHEME 5 biradical intermediates have a very short life enabling them to equilibrate to the most stable one. In the case of 1-methyl1-phenyl-1-(2-furyl)methanol, if the hydroxyl group drives the attack of the oxygen of the carbonyl group, we obtained the conformations of the biradical intermediate represented in Figure 14.

We can observe that $\mathrm{AB}$ and $\mathrm{AD}$ are the preferred conformations. Calculations on these conformations showed that there is a difference of $13.26 \mathrm{~kJ} \mathrm{~mol}^{-1}$ between the energies of these two conformations (AD is the most stable one). This difference can account for the observed complete diastereoselectivity of the reaction. In the reaction of the same substrate with benzophenone the corresponding conformers $\mathbf{A B}$ and $\mathrm{AD}$ show an energy difference of $7.79 \mathrm{~kJ} \mathrm{~mol}^{-1}$ : this difference is in agreement with the observed diastereoselectivity.

Figure 15 reports the possible conformations of 1-methyl-1-t-butyl-1-(2-furyl)methanol.

On the basis of these conformers, if the attachment of the excited carbonyl compound occurs on the prochiral face of the furan ring where the hydroxyl group is present, the conformers in Figure 15 can be obtained.

The conformers of Figure 15 differ by $6.90 \mathrm{~kJ} \mathrm{~mol}^{-1}$, in agreement with the observed diastereoisomeric excess.

To test the above-described hypothesis we examined also the results obtained on 2-furylmethanol derivatives. The reaction of 2-furylphenylmethanol gave complete diastereoisomeric control when it reacted with benzophenone [37]. The conformers of this substrate are reported in Figure 16. The conformers deriving from the attack of the excited carbonyl compound on the prochiral face of the furan ring where the hydroxyl group is present are described in Figure 16.

AI is the most stable conformer of the $(R R)^{*}$ biradical, while AL represents the most stable conformer of $(R S)^{*}$ 


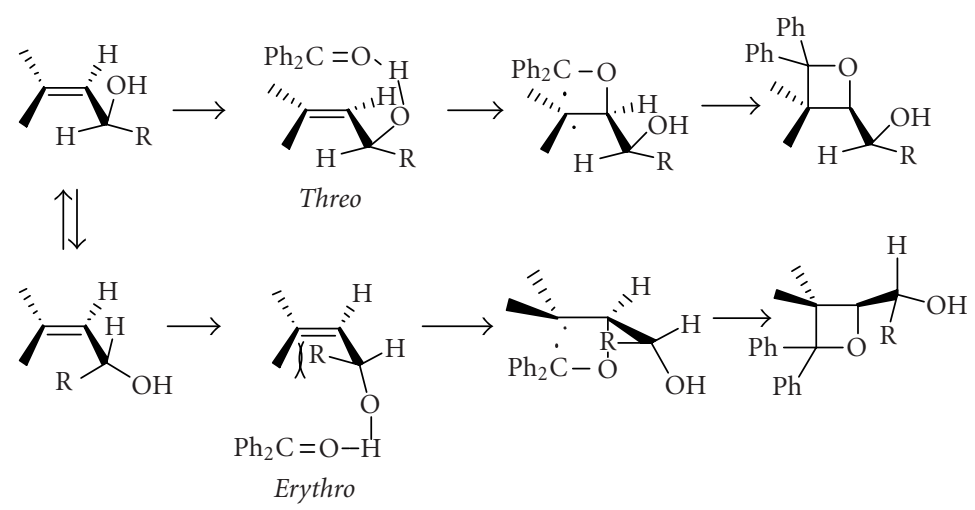

SCHEME 6

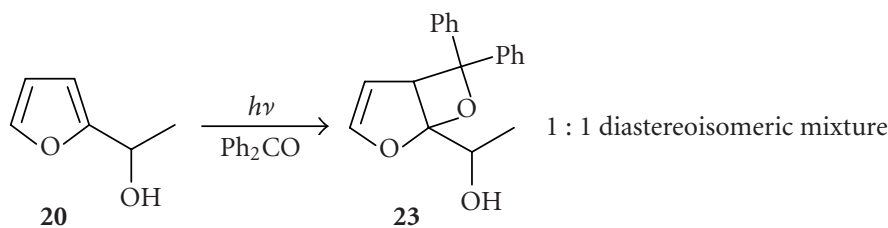<smiles>[Z10]C(=O)OCC(=O)OCCOc1ccccc1</smiles>

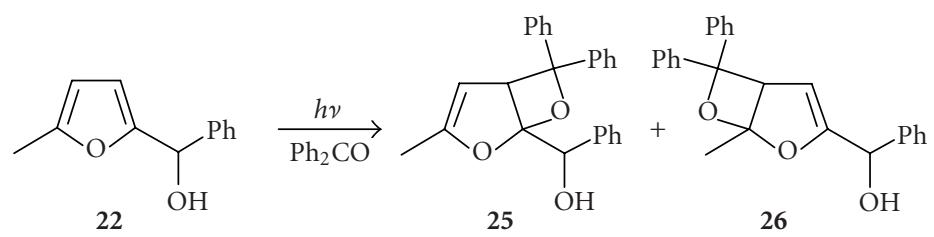<smiles>CC(O)c1ccco1</smiles>

SCHEME 7

biradical. The conformer AL is more stable than AI by $16.57 \mathrm{~kJ} \mathrm{~mol}^{-1}$, in agreement with the observed high diastereoselectivity. Furthermore, the same compound reacted with acetone to give the corresponding adduct without diastereoselectivity. Also in this case conformers AI and AL are those showing lowest energy but the difference between them is $1.09 \mathrm{~kJ} \mathrm{~mol}^{-1}$, in agreement with the observed lack of diastereoselectivity.

The same approach can be used to justify the stereocontrol of the reaction of allylic alcohols with benzophenone [41].

\section{CONCLUSION}

In conclusion we have shown that the regiocontrol of the attack of the benzaldehyde on the double bond is related to the different stability of the biradical intermediates. The endo stereoselectivity of the reaction depends on the superposition between HSOMO and LSOMO in the biradical intermediate. The regiocontrol depends on the relative stability of the possible biradical intermediates. The exo stereoselectivity of the coupling reaction depends on the superposition between the HSOMO and LSOMO of the biradical intermediate. 


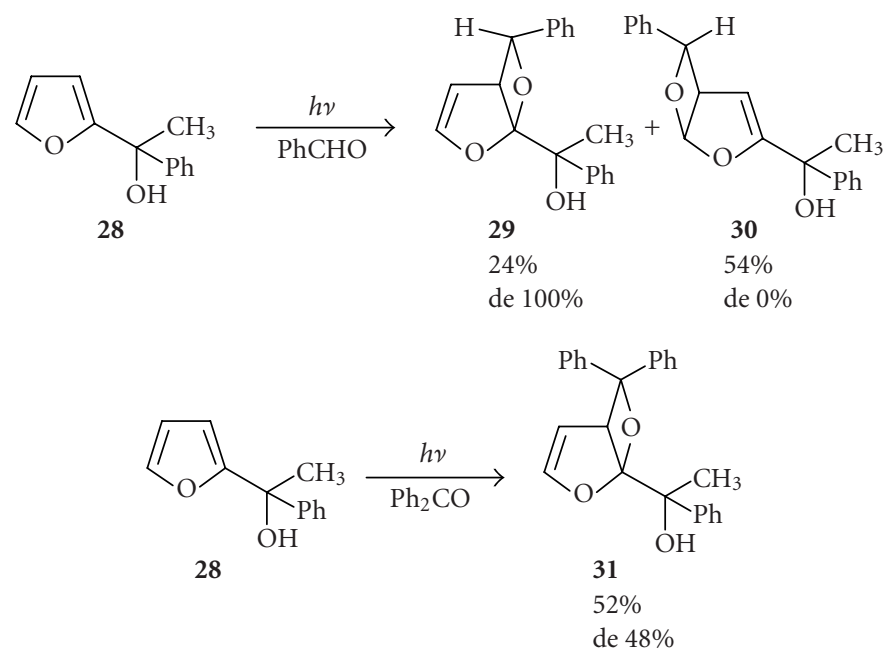

SCHEMe 8<smiles>CC(O)(Br)c1ccco1</smiles>

32<smiles>CCOc1ccccc1</smiles><smiles>CC(O)(Br)C1(C(=O)Br)OC=CC1c1ccccc1</smiles><smiles>CC(O)(Br)c1ccco1</smiles>
32<smiles>O=C(O)c1ccccc1</smiles><smiles>CC(O)(Br)C12OC=CC1C(c1ccccc1)(c1ccccc1)O2</smiles>

SCHEMe 9

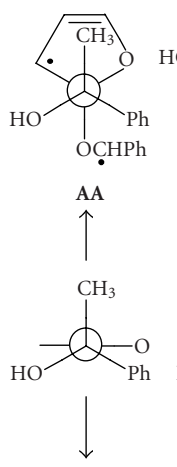

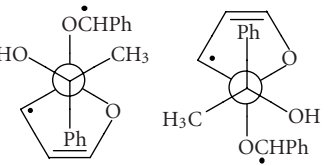<smiles>CC1(O)C2CC3OC(O2)C3(O)C1(O)O</smiles>

$\mathrm{AB}$
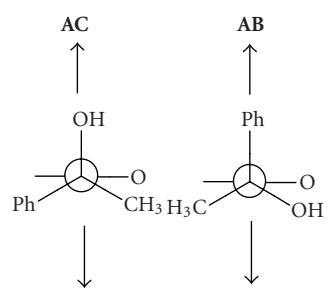<smiles>OC1([OH2+])C2C=CC(O2)C1(O)c1ccccc1</smiles>

$\mathrm{AD}$
Figure 14: Possible conformations of the biradical intermediate from the reaction of 1-methyl-1-phenyl-1-(2-furyl)methanol with benzaldehyde.

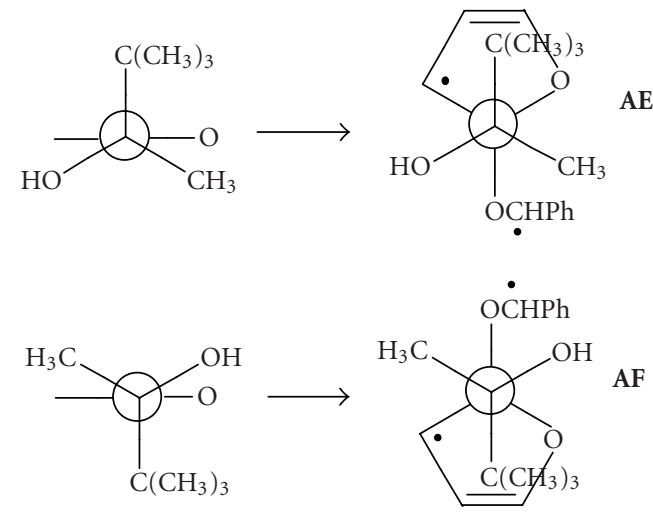

FIgURE 15: Possible conformations of the biradical intermediate from the reaction of 1-methyl-1-t-butyl-1-(2-furyl)methanol with benzaldehyde. 


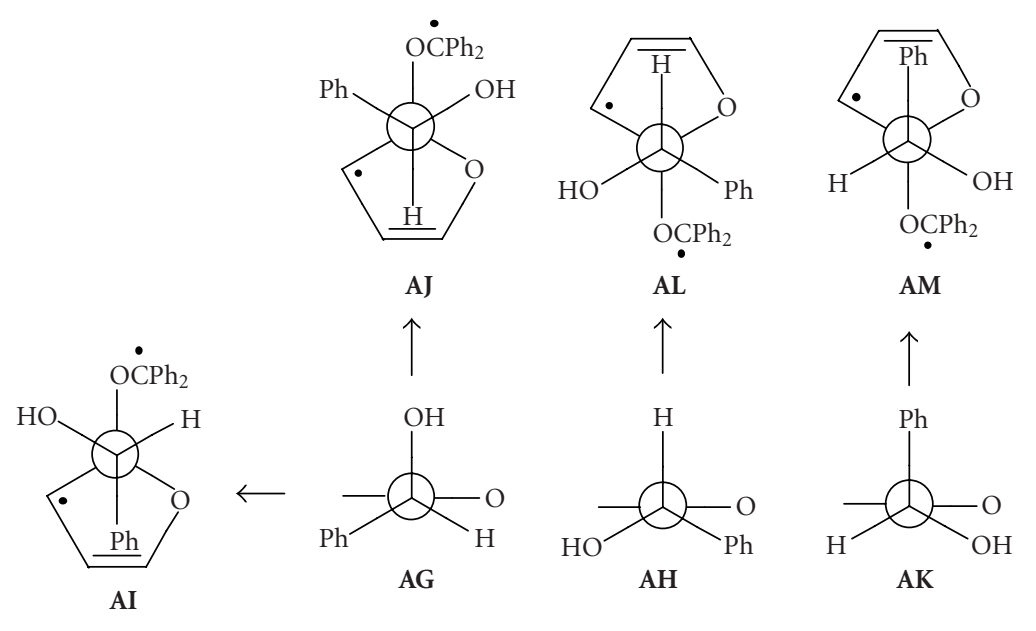

Figure 16: Possible conformations of the biradical intermediate from the reaction of 2-furylphenylmethanol with benzophenone.

this field: some hypotheses able to explain the simple stereoselectivity observed in the reaction between furan and benzaldehyde have been reported. This selectivity has to be confirmed studying the photochemical behavior of other carbonyl compounds, in particular heterocyclic carbonyl compounds. We have only very few data on furan- and thiophene-2-carbaldehyde [42-44]. In particular, the possible role of the excited singlet state in this reaction has to be explained, and some heterocyclic aldehydes have a long half-life.

Diastereoselective synthesis has been performed by using chiral substrates. It is not clear if this behaviour is a general character of this reaction: we need to test this behavior on a large number of chiral ketones.

High stereoselectivity was observed in the reaction between 2-furylmethanol derivatives and carbonyl compounds. We do not know the photochemical behaviour of 3 -furylmethanol derivatives.

\section{REFERENCES}

[1] T. Bach, "Stereoselective intermolecular $[2+2]$-photocycloaddition reactions and their application in synthesis," Synthesis, vol. 1998, no. 5, pp. 683-703, 1998.

[2] E. Paternò and G. Chieffi, "Sintesi in chimica organica per mezzo della luce. Nota II. Composti degli idrocarburi non saturi con aldeidi e chetoni," Gazzetta Chimica Italiana, vol. 39, p. 341, 1909.

[3] G. Büchi, C. G. Inman, and E. S. Lipinsky, "Light-catalyzed organic reactions. I. The reaction of carbonyl compounds with 2-methyl-2-butene in the presence of ultraviolet light," Journal of the American Chemical Society, vol. 76, no. 17, pp. 43274331, 1954.

[4] G. Ciamician, "The photochemistry of the future," Science, vol. 36, pp. 385-394, 1912.

[5] I. J. Palmer, I. N. Ragazos, F. Bernardi, M. Olivucci, and M. A. Robb, "An MC-SCF study of the (photochemical) PaternòBüchi reaction," Journal of the American Chemical Society, vol. 116, no. 5, pp. 2121-2132, 1994.

[6] S. C. Freilich and K. S. Peters, "Observation of the 1,4 biradical in the Paternò-Büchi reaction," Journal of the American Chemical Society, vol. 103, no. 20, pp. 6255-6257, 1981.
[7] S. C. Freilich and K. S. Peters, "Picosecond dynamics of the Paternò-Büchi reaction," Journal of the American Chemical Society, vol. 107, no. 13, pp. 3819-3822, 1985.

[8] A. G. Kutateladze, "Conformational analysis of singlet-triplet state mixing in Paternò-Büchi diradicals," Journal of the American Chemical Society, vol. 123, no. 38, pp. 9279-9282, 2001.

[9] M. D’Auria, L. Emanuele, R. Racioppi, and G. Romaniello, "The Paternò-Büchi reaction on furan derivatives," Current Organic Chemistry, vol. 7, no. 14, pp. 1443-1459, 2003.

[10] M. D’Auria, L. Emanuele, and R. Racioppi, “1, 2-Cycloaddition reaction of carbonyl compounds and pentaatomic heterocyclic compounds," in Advances in Photochemistry, D. C. Neckers, W. S. Jenks, and T. Wolff, Eds., vol. 28, pp. 81-127, John Wiley \& Sons, Hoboken, NJ, USA, 2005.

[11] H. Buschmann, H.-D. Scharf, N. Hoffmann, and P. Esser, "The isoinversion principle - a general model of chemical selectivity," Angewandte Chemie - International Edition in English, vol. 30, no. 5, pp. 477-515, 1991.

[12] A. G. Griesbeck, S. Buhr, M. Fiege, H. Schmickler, and J. Lex, "Stereoselectivity of triplet photocycloadditions: 1 dienecarbonyl reactions and solvent effects," Journal of Organic Chemistry, vol. 63, no. 12, pp. 3847-3854, 1998.

[13] M. Abe, T. Kawakami, S. Ohata, K. Nozaki, and M. Nojima, "Mechanism of stereo- and regioselectivity in the PaternòBüchi reaction of furan derivatives with aromatic carbonyl compounds: importance of the conformational distribution in the intermediary triplet 1,4-diradicals," Journal of the American Chemical Society, vol. 126, no. 9, pp. 2838-2846, 2004.

[14] A. G. Griesbeck, M. Abe, and S. Bondock, "Selectivity control in electron spin inversion processes: regio- and stereochemistry of Paternò-Büchi photocycloadditions as a powerful tool for mapping intersystem crossing processes," Accounts of Chemical Research, vol. 37, no. 12, pp. 919-928, 2004.

[15] M. D'Auria, "Paternò-Büchi reaction on furan: regio- and stereochemistry," in Targets in Heterocyclic Systems, Chemistry and Properties, O. A. Attanasi and D. Spinelli, Eds., vol. 7, pp. 157-173, Italian Society of Chemistry, Rome, Italy, 2003.

[16] M. Ogata, H. Watanabe, and H. Kano, "Photochemical cycloaddition of benzophenone to furans," Tetrahedron Letters, p. 533, 1967.

[17] H. A. J. Carless and D. J. Haywood, "Photochemical syntheses of 2,6-dioxabicyclo [3.2.0] heptanes," Journal of the Chemical 
Society, Chemical Communications, no. 22, pp. 1067-1068, 1980.

[18] A. G. Griesbeck and S. Stadtmüller, "Photocycloaddition of benzaldehyde to cyclic olefins: electronic control of endo stereoselectivity," Journal of the American Chemical Society, vol. 112, no. 3, pp. 1281-1283, 1990.

[19] A. G. Griesbeck and S. Stadtmüller, "Electronic control of stereoselectivity in photocycloaddition reactions. 4. Effects of methyl substituents at the donor olefin," Journal of the American Chemical Society, vol. 113, no. 18, pp. 6923-6928, 1991.

[20] A. G. Griesbeck and S. Stadtmüller, "Regio-und Stereoselektive Photocycloadditionen Aromatischer Aldehyde an Furan und 2,3-Dihydrofuran," Chemische Berichte, vol. 123, pp. 357$362,1990$.

[21] G. O. Schenck, R. Hartman, and R. Steinmetz, "Vierringsynthesen durch photosensibilisierte cycloaddition von dimethylmaleinsäurenhydrid an olefine," Chemische Berichte, vol. 96, p. 498, 1963.

[22] D. Gagnaire and E. Payo-Subiza, "Couplage des protons d'un méthyle à travers cinq liaisons en resonance magnétique nucléaire: ethers vinyliques hétérocycliques," Bulletin de Société Chimique de France, p. 2623, 1963.

[23] S. Toki, K. Shima, and H. Sakurai, "Organic photochemical reactions. I. The synthesis of substituted oxetanes by the photoaddition of aldehydes to furans," Bulletin of the Chemical Society of Japan, vol. 38, no. 5, pp. 760-762, 1965.

[24] T. Nakano, C. Rivas, C. Perez, and K. Tori, "Configuration and stereochemistry of photoproducts by application of the nuclear Overhauser effect. Adducts of benzophenone with methyl-substituted furans and 2,5-dimethylthiophen, and of methyl-substituted maleic anhydrides with thiophen and its methyl derivatives, and benzo-[b]thiophen," Journal of the Chemical Society, Perkin Transactions 1, pp. 2322-2327, 1973.

[25] E. B. Whipple and G. R. Evanega, "The assignment of configuration to the photoaddition products of unsymmetrical carbonyls to furan using pseudocontact shifts," Tetrahedron, vol. 24, no. 3, pp. 1299-1310, 1968.

[26] M. D’Auria, L. Emanuele, and R. Racioppi, "On the PaternòBüchi reaction of chiral phenylglyoxylate esters with furan derivatives," Photochemical and Photobiological Sciences, vol. 2, no. 9, pp. 904-913, 2003.

[27] M. D’Auria, L. Emanuele, and R. Racioppi, "Diastereoselectivity in the Paternò-Büchi reaction on furan derivatives," Tetrahedron Letters, vol. 45, no. 20, pp. 3877-3880, 2004.

[28] M. D’Auria, L. Emanuele, V. Pace, and R. Racioppi, "Diastereoselective Paternò-Büchi reaction on furan derivativesreaction with asymmetric ketones," Letters in Organic Chemistry, vol. 3, no. 5, pp. 244-246, 2006.

[29] W. Adam, K. S. Peters, E. M. Peters, and V. R. Stegmann, "Hydroxy-directed regio- and diastereoselective [2+2] photocycloaddition (Paternò-Büchi reaction) of benzophenone to chiral allylic alcohols," Journal of the American Chemical Society, vol. 122, no. 12, pp. 2958-2959, 2000.

[30] W. Adam and V. R. Stegmann, "Hydroxy-group directivity in the regioselective and diastereoselective $[2+2]$ photocycloaddition (Paternò-Büchi reaction) of aromatic carbonyl compounds to chiral and achiral allylic substrates: the preparation of oxetanes with up to three stereogenic centers as synthetic building blocks," Synthesis, no. 8, pp. 1203-1214, 2001.

[31] M. Prein and W. Adam, "The schenck ene reaction: diastereoselective oxyfunctionalization with singlet oxygen in synthetic applications," Angewandte Chemie - International Edition, vol. 35, no. 5, pp. 477-494, 1996.
[32] A. G. Griesbeck and S. Bondock, "Paternò-Büchi reactions of allylic alcohols and acetates with aldehydes: hydrogen-bond interaction in the excited singlet and triplet states?" Journal of the American Chemical Society, vol. 123, no. 25, pp. 6191-6192, 2001.

[33] T. Bach, J. Schröder, and K. Harms, "Diastereoselective photocycloaddition of an axial chiral enamide," Tetrahedron Letters, vol. 40, no. 51, pp. 9003-9004, 1999.

[34] T. Bach, H. Bergmann, and K. Harms, "High facial diastereoselectivity in the photocycloaddition of a chiral aromatic aldehyde and an enamide induced by intermolecular hydrogen bonding," Journal of the American Chemical Society, vol. 121, no. 45, pp. 10650-10651, 1999.

[35] A. Yokoyama and K. Mizuno, "Stereoselective photocycloaddition of alkenes to naphthalene rings assisted by hydrogen bonding," Organic Letters, vol. 2, no. 22, pp. 3457-3459, 2000.

[36] T. Bach, "The Paternò-Büchi reaction of 3-heteroatomsubstituted alkenes as a stereoselective entry to polyfunctional cyclic and acyclic molecules," Liebigs Annalen, vol. 1997, no. 8, pp. 1627-1634, 1997.

[37] M. D’Auria, R. Racioppi, and G. Romaniello, “The PaternòBüchi reaction of 2-furylmethanols," European Journal of Organic Chemistry, no. 19, pp. 3265-3272, 2000.

[38] M. D'Auria and R. Racioppi, "Paternò-Büchi reaction on 5methyl-2-furylmethanol derivatives," Arkivoc, vol. 2, part II, pp. 133-140, 2000.

[39] M. D’Auria, L. Emanuele, G. Poggi, R. Racioppi, and G. Romaniello, "On the stereoselectivity of the Paternò-Büchi reaction between carbonyl compounds and 2-furylmethanol derivatives. The case of aliphatic aldehydes and ketones," Tetrahedron, vol. 58, no. 25, pp. 5045-5051, 2002.

[40] M. D’Auria, L. Emanuele, and R. Racioppi, “The stereoselectivity of the Paternò-Büchi reaction between tertiary 2furylmethanol derivatives and aromatic carbonyl compounds: on the nature of the hydroxy directing effect," Photochemical and Photobiological Sciences, vol. 3, no. 10, pp. 927-932, 2004.

[41] M. D’Auria, L. Emanuele, and R. Racioppi, "Stereoselectivity in the Paternò-Büchi reaction on chiral allylic alcohols, for a discussion of the hydroxy directing effect," Letters in Organic Chemistry, vol. 2, no. 2, pp. 132-135, 2005.

[42] K. Shima and H. Sakurai, "Organic photochemical reactions. IV. Photoaddition reactions of various carbonyl compounds to furan," Bulletin of the Chemical Society of Japan, vol. 39, no. 8, pp. 1806-1808, 1966.

[43] T. S. Cantrell, A. C. Allen, and H. Ziffer, "Photochemical $2+2$ cycloaddition of arenecarboxylic acid esters to furans and 1,3dienes. $2+2$ Cycloreversion of oxetanes to dienol esters and ketones," Journal of Organic Chemistry, vol. 54, no. 1, pp. 140145, 1989.

[44] C. Rivas, R. A. Bolivar, and M. Cucarella, "Photoaddition of carbonyl compounds to five-membered ring heterocycles," Journal of Heterocyclic Chemistry, vol. 19, p. 529, 1982. 


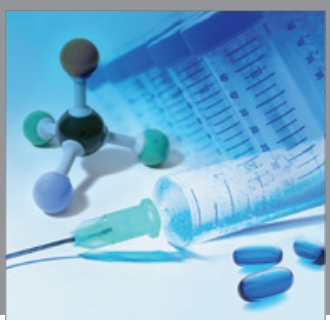

International Journal of

Medicinal Chemistry

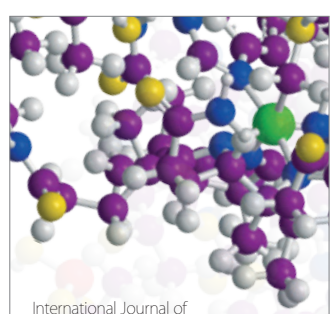

Carbohydrate Chemistry

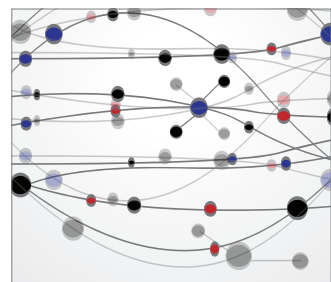

The Scientific World Journal
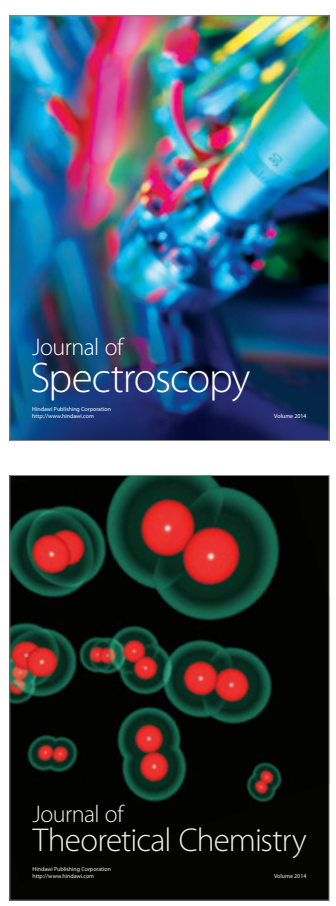
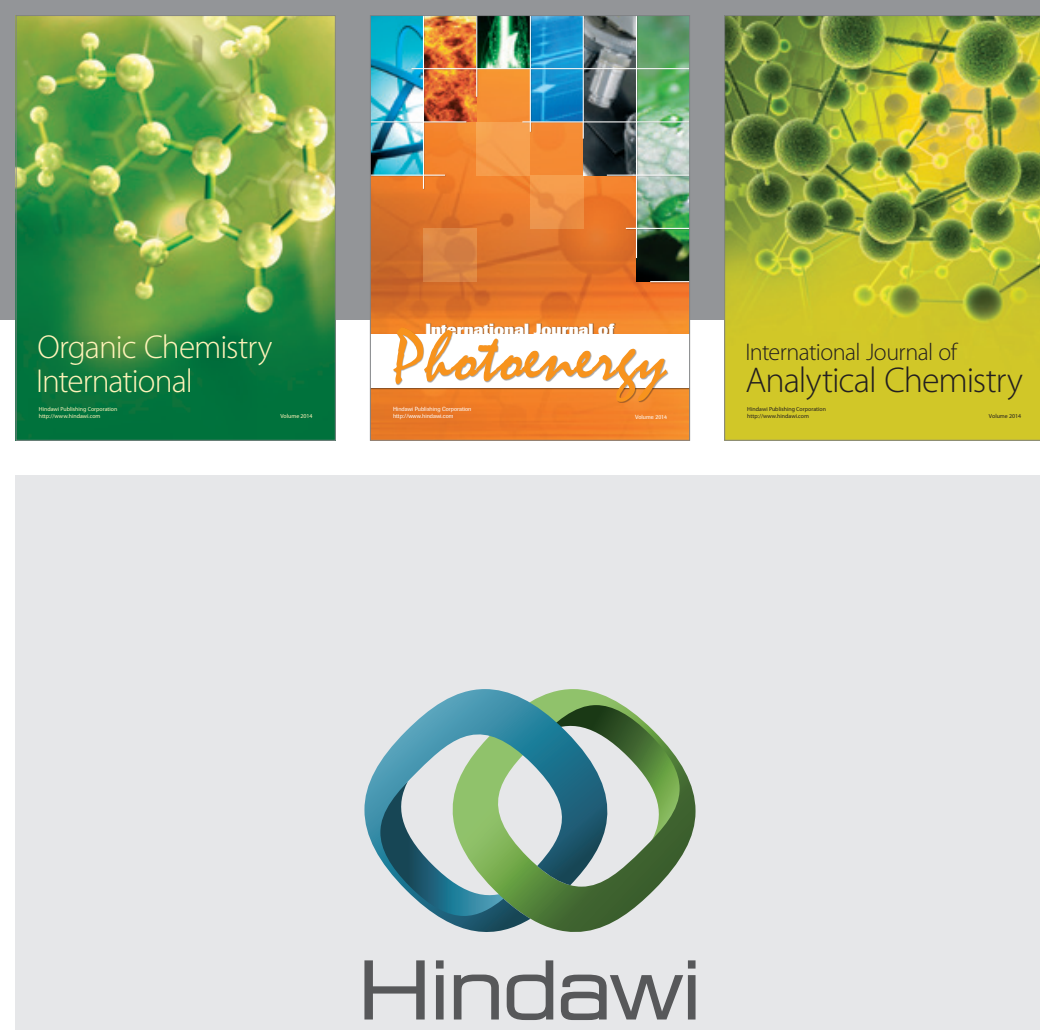

Submit your manuscripts at

http://www.hindawi.com
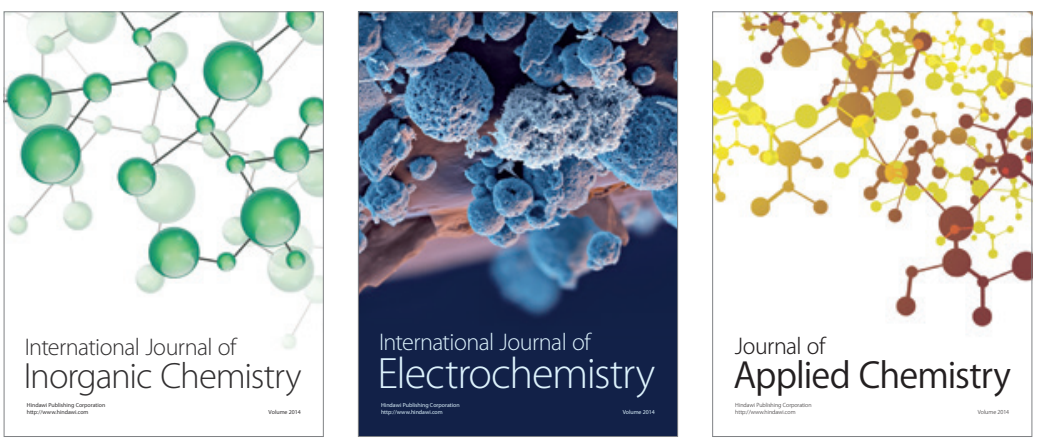

Journal of

Applied Chemistry
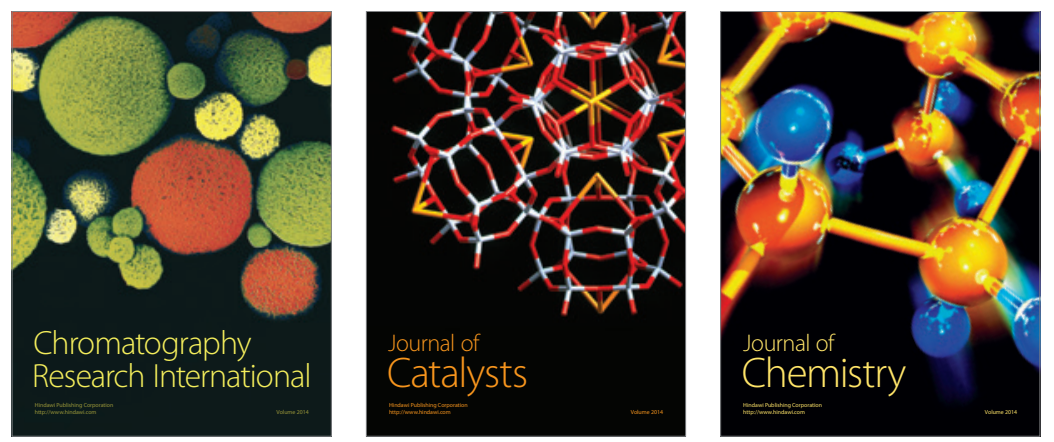
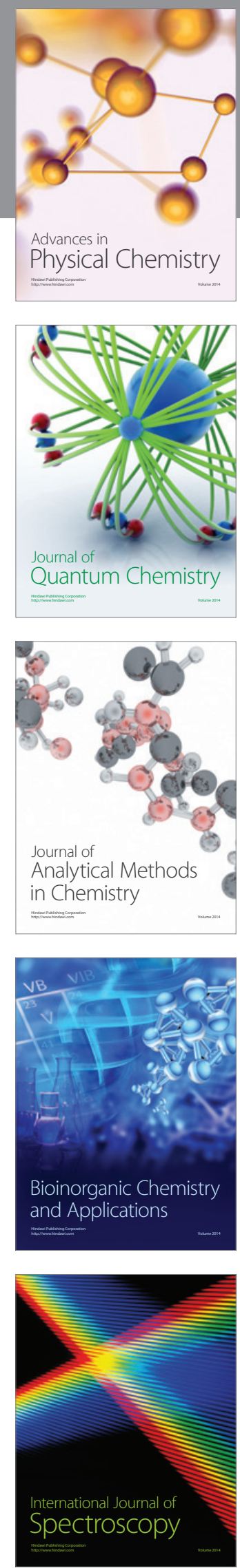